\title{
Learning Chinese Characters via Mobile Technology in a primary school classroom
}

\author{
Jie Lu $\mathbf{~}^{1}$ \\ jielu@hku.hk \\ Sue Mang ${ }^{2}$ \\ mengsue2011@gmail.com \\ Vincent Tam $^{3}$ \\ vtam@eee.hku.hk \\ ${ }^{1}$ Faculty of Education, The University of Hong Kong \\ ${ }^{2}$ School of Chinese, The University of Hong Kong \\ ${ }^{3}$ Faculty of Education, The University of Hong Kong
}

\begin{abstract}
This paper describes a project including design, development and use of a mobile application (App) for learning Chinese as second language in a bilingual primary school. The App was designed for iPad Touch Apple technology with the purpose to facilitate learning of a fundamental set of 200 Chinese characters. The project was a coordinated effort of experts including an instructional designer, a software engineer, a Chinese language expert, and classroom teachers to develop an experimental Chinese Character learning App for the primary school classroom. This paper reports how the project team explored experiences of teachers and learners in a particular context, developed understanding of teaching and learning needs for Chinese language learning, and how these inform design of the educational App. The final outcomes of the project include a Chinese characters learning App and recommendations for design and use of educational Apps in Chinese language teaching and other similar contexts.
\end{abstract}

Keywords: Mobile Application, Chinese Language learning as Second Language, Mobile Learning

\section{Background}

The emergency and wide adoption of mobile technology, such smart phones and Tablet PCs, creates promising opportunities for learning anywhere and anytime. Use s of such technology in education is referred in literature to as mobile learning (e.g. Kukulska-Hulme, \& Traxler, 2007; Motiwalla, 2007). The contemporary mobile technology is powerful in terms of its mobility and connectivity, large screen sizes, easy-to-use multimedia production and sharing tools, and tangible user interfaces (Churchill, Fox \& King, 2012). Potential of mobile technology has been driving many educators to explore it in teaching and learning. Along with the spread of mobile technology, an increasing number of mobile applications (referred to as App hereafter) are emerging in markets. Although many of them have been designed to support learning English, little work has been done for Chinese language education. It is also noteworthy that many educational Apps are designed by software engineers without proper consultations with instructional design experts, and thus the usability of these Apps in education don’t always meet expectation.

Chinese language is evoking interests from non-native speakers around the world due to the economical, cultural and political rise of China, and has poses barriers to many foreign learners. In this context, a Chinese character learning App 
was developed by our team in 2010 for university students to learn some fundamental set of Chinese Characters via Pocket PC technology. This App has been titled Mobilese (see Figure 1). The core content of this App is a set of character templates, and animated characters following which student can practice writing stroke by stroke, hear pronunciation in Cantonese or Putonghua, and explore similar characters and examples of related words . The App is able to detect whether the stroke order and formation are correctly executed, and generate instant feedback based on writing performance so that learners can correct their mistakes. This set of Chinese characters was chosen by a Chinese language expert as a fundamental base to equip beginning learners with essential understandings for further learning.

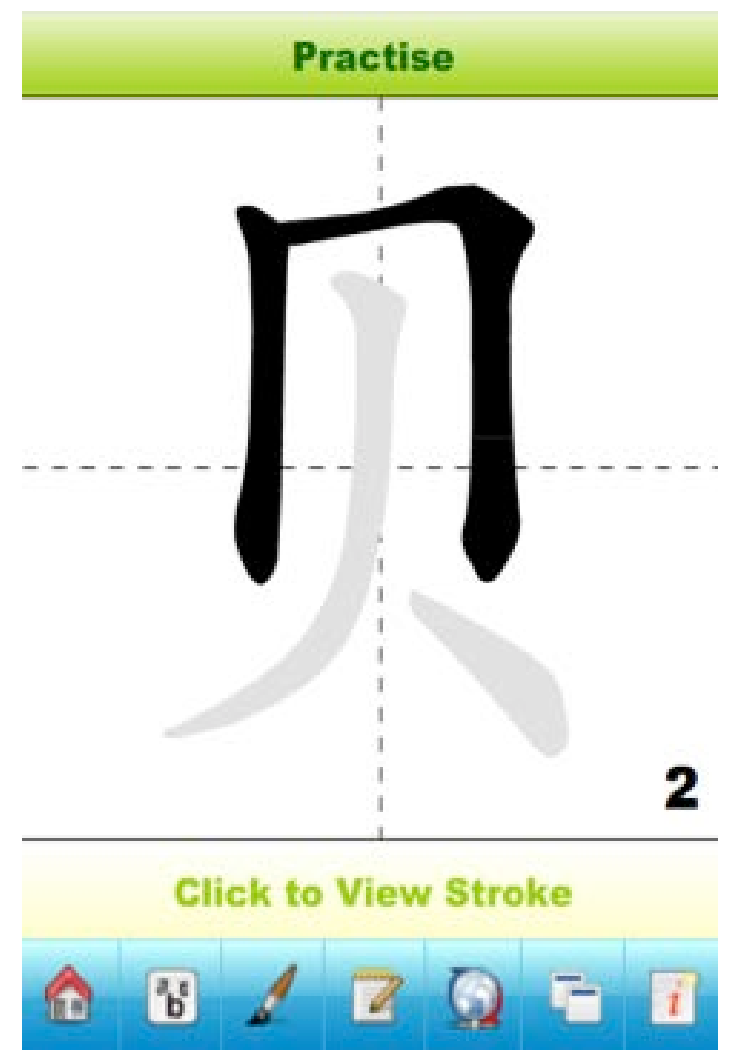

Figure 1. Screenshot of Mobilese

Since 2010, a number of schools in Hong Kong have begun to deployed one-to-one mobile device programs where each student is equipped with a mobile device (e.g., iPad) to assist learning. Among these schools, one showed interest in the App and thus funded our project to further develop it for beginning primary school children's use via iPod Touch technology. The sponsoring school admits children from diverse cultural backgrounds, including both Chinese and nonChinese children. Dual-language programmes in English and Chinese are offered. This diversity of students has challenged teachers. In terms of Chinese language learning, for example, children from non-native speaking families have to spend more efforts and a longer time studying the fundamental concepts. Differentiated instruction has been implemented to tackle this issue. Administrators of the school expected that by bringing the App into the classroom, learning engagement could be enhanced, and students with various learning abilities could effectively acquire knowledge essential for learning of Chinese characters and language in general.

This paper reports how the project team gained understanding of pedagogical requirements of teachers and students in the context of a bilingual primary school, and how these understanding informed further development of the initial version of the App. The usefulness of the App for learning Chinese characters was evaluated in the classroom. Based on experiences of the project, recommendations are put forward for using the App in the context of Chinese learning as foreign language.

\section{About the Project}


The goal of the project was to further develop Mobilese App into a version suitable for early primary school students to learn Chinese characters via their iPod technology. Designing educational software should build upon multidisciplinary expertise (Abras, Maloney-Krichmar, \& Preece, 2004).. In this sense, the project team recruited an instructional designer, a software engineer, a Chinese language expert, and four classroom teachers. Four main stages were undertaken for redesign purpose, as shown in Table 1.

Table 1

Phases of the App Development and Evaluation

\begin{tabular}{ll}
\hline Phase & Activities in sequential order \\
\hline $\begin{array}{l}\text { Requirement } \\
\text { analysis }\end{array}$ & (1) Reviewing and analysing literature on learning of Chinese characters \\
& (2) Gaining understanding of school context through classroom observations, \\
(3) Analysing pedagogical needs and requirements of teachers and students \\
Design & (4) Interpreting results of requirement analysis to determine system \\
(5) Recification \\
(6) Desiewing and analysing literature to assist decision-making in functional \\
(7) Evaluating prototype with teachers and revising system with collected \\
feedback for improvement \\
(8) Translating design into the App product \\
Evaluation \\
(9) Evaluating usefulness of the App through classroom observations, \\
interviews with teachers and students, and analysis of learning artefacts. \\
\hline
\end{tabular}

\section{App Design and Development}

\subsection{Requirement Analysis}

The review of literature on Chinese language learning suggests three common challenges of studying Chinese characters. The first challenge is developing the structural awareness of characters. Chinese characters are composed from a combination of eight basic strokes and their variations. Strokes are arranged into suitable areas in relation to one another. The awareness of the character's internal structure significantly affects children's recognition as well as reading of the characters (Tan, Spinks, John, Eden, Perfetti, \& Siok, 2005). If students are instructed how a character is constructed step by step, then they likely memorize it in an organized way (Shen, 2004). The second is executing correct stroke order while practicing the writing of the character. A stroke is the basic unit of Chinese writing. The execution of the correct stroke sequence has traditionally been suggested as the key in accurate production and recognition of Chinese characters (Giovanni, 1994). However, primary school students often meet difficulties, and make errors in stroke sequencing, even after repeatedly taught stroke order rules (Law, Ki, Chung, Ko, Lam, 1998). The third is related to challenge with pronunciation (So \& Siegel, 1997). Chinese characters are not phonetic, that is, the stroke components of a character do not equate a syllable with a particular tone. Unlike English, the tone of a Chinese character is directly associated with its meaning. What makes it more complicated is that a considerable portion of Chinese characters corresponds to more than one pronunciation. Additional mental effort has to be made to associate the pronunciation of each character with its written form. Pinyin is suggested as an effective tool to facilitate pronunciation for beginner learners (Wang \& Leland, 2011).

With these three suggestions in mind, the team generated a list of questions that should be addressed in subsequent teacher interviews and classroom observations. Some of guiding questions were:

(1) What are challenges and difficulties of mastering characters faced by your students?

(2) How can students be assisted to overcome these challenges and difficulties?

(3) How do you think the App could be designed support your teaching design? 
(4) How do you think the App should be designed to facilitate learning of Chinese characters?

Four Year 1 Chinese language teachers shared their insights regarding pedagogical needs that the App should address in their classrooms. From their point of view, the potential role of the App was to support the implementation of differentiated instruction so that all students could learn effectively, regardless of their learning abilities, needs, and preferences. The App should be aimed to enable students to learn and practice Chinese characters at their own paces. The teachers confirmed the three suggested challenges identified in the literature. Furthermore, they emphasized that the problem of executing correct stroke order for their non-native speaker children was the most prominent. To address this, the App should be designed to offer learners adequate scaffolding during the writing process. Enhancing children's learning interests by using game-based features was suggested by the teachers as well because children were often distracted during learning due to their short attention spans.

The instructional designer attended a total of eight lessons over one month. The classroom observations focused mainly on recording classroom dynamics and activities. It was observed that, after teachers' demonstrations, students typically practiced handwriting of new characters with their workbooks again and again. Students pronounced the stroke names during the writing process. To facilitate personal meaning making, students were required to write down sentences incorporating the new characters and share the sentences by speaking out loudly in front of class. Sentence construction seemed to be rather difficult for those whose vocabulary was limited. Teachers usually grouped students according to their levels of Chinese language abilities, and activities of appropriate difficulty levels were assigned to different groups, such as practicing writing on workbook for lower level ability students and storytelling for higher level ability ones. In group activities, students learnt in a more self-directed and independent way under the limited teachers' supervision

The pedagogical needs identified from teacher interviews and classroom observations are summarized:

- $\quad$ Enabling games to make learning a fun and enjoyable process

- $\quad$ Supporting self-paced individual learning

- Demonstrating pronunciation and writing in an effective manner

- Enhancing the existing learning process of writing, reading, and meaning of characters in the classroom

- Reinforcing character pronunciation

- Scaffolding students to write characters in correct stroke order

- Archiving students' learning artifacts for student reflection and teacher assessment

The design of educational App should take target learner's technical competency and attitude into consideration. In this project, seventeen Year 1 students were invited to participate a short tell-and-show session. These students were recommended by teachers (1) ranging from low to high levels of Chinese language abilities, and (2) native and nonnative Chinese speakers. Among them, ten were boys and seven girls. They were five to six years old. Each of the participating children was asked to answer a few simple questions while showing the researcher how they manipulated an iPod Touch. Formal consents were obtained from their teachers, parents, and school principle. Two general questions guided the student tell-and-show: "Do you like the iPod Touch? Why?” and "What can you do with the iPod Touch?” The results revealed that all of the students were capable of operating an iPod Touch for media capturing and playing tasks, such as listening to stories, capturing photos, and taking videos. They could operate the mobile application using simple gestures, such as swiping and tapping. All of them enjoyed playing games with the iPod Touch. For children five to six years of age growing up with various advanced digital devices, they had mastered the basic technical proficiency to learn with mobile devices.

In summary, through requirement analysis, the project team built understanding of the pedagogical context in which the App would be used. These understandings then informed the App design in the next phase.

\subsection{Design and Development of the App}

The team analysed the user requirements and other related work including existing Chinese learning App and literature on Chinese language learning. Agreements were reached on App’s system functionality (see Table 3). During the design process, prototypes with limited functions were shown to four teachers for suggestions on user interfaces and functions. 
These suggestions were then taken back to design plan. The App was finally designed to consist of four main functional modules: Character Library, Learning Games, My Collection, and My Handbook.

\section{Table 2}

System Requirements of the App

\begin{tabular}{ll}
\hline Pedagogical needs & $\begin{array}{l}\text { Functional Design to address specific pedagogical needs } \\
\text { identified }\end{array}$
\end{tabular}

(1) Enable games to make learning a fun and enjoyable process

(2) Support self-paced individual learning

(3) Demonstrate pronunciation and writing in an effective manner

(4) Enhance the existing learning process of writing, speaking, and meaning of characters in classroom

(5) Scaffold students to write characters in correct stroke order

(6) Reinforce learning of character pronunciation

(7) Archive students' learning artifacts for student reflection and teacher assessment
- $\quad$ Show Pinyin along with the character (3) (4)

- $\quad$ Add audio pronunciations (3)(4)(6)

- Illustrate the entire process of writing a character stroke by stroke (2)(3)

- Allow students to directly write on screens of their IPod Touch following animated hints. (2)(5)

- $\quad$ Provide instant feedback when students properly finish writing a character or make mistakes (2)(5)

- Audio record students' speaking and enable playback (2)(3)(4) (6)(7)

- Exercise associating pinyin with correct characters in the form of games (1)(2) (3)(4)(6)

- Show words composed of the character (2)(3)(4)

- Allow students to take photos of real-world objects related to the meaning of the character (4)

- $\quad$ Archive students’ learning artifacts (7)

- Record information related to the application's learning activities (7)

\subsubsection{Character Library Module}

Character Library consists of six units of Chinese characters suggested by teachers. This is the main venue where learners may learn and practice writing, listening, speaking, and reading characters. The combination of animation, audio, and pictures creates a multimedia-learning environment for learners. Figure 2 is the first screen of the module. As illustrated in the Figure 1, characters in the library are categorized by (a) Pinyin, (b) the number of strokes, and (c) learning unites defined by a teachers. By scrolling the "Character" pane in the upper side of the interface, learners select one of characters from a collection which is sorted based on aforementioned three categorizations. In addition, the App enables students to tag and categorize characters according to their preferences ("Like") or/and learning progress ("Need to Know" and "Know"). Such a learner-centred feature helps create opportunities for children to manage and monitor their own learning process. Learners may also select a character from their own defined collections from the pane in the lower side of the interface. Personalized categorization of learning content can help individuals to more effectively manage and retrieve their learning materials and resources, and promote self-directed learning (Estellés \& Moral, 2010). 


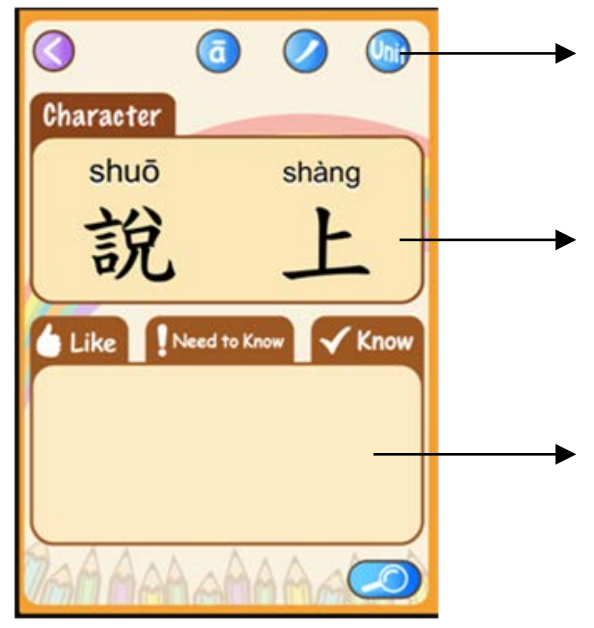

Choose to view characters in the library sorted by Pinyin, the number of strokes, and learning units

Select a character from the library

Select a character from "Like", "Need to know" or "Know" collection. The character is sorted into one or more collections formerly on the second screen of Character Library.

Figure 2. The first screen of Character Library

After selecting a character, learners are navigated to the second screen to learn and practice it, as shown in Figure 3. Learners are enabled to freely choose to (a) watch the animated illustration of writing the character stroke by stroke, which indicates the start and the end of each of strokes, (b) follow the animated hints to practice writing with fingers, (c) take screenshots of their writing, (d) learn related pinyin and hear the audio pronunciation, (e) record their speaking and play it back, (f) browse the related words, and (g) take photos of real-world objects associated with the meaning of a particular character. The design rationales behind feature designs of the Character Library module are: (a) multimodality and interactivity of educational courseware assist understanding of conceptual knowledge (Churchill, 2008), (b) Strokeby-stroke illustration of writing a character through animation can potentially enhance structural understanding of the Chinese character and then improve writing and recognition (Wang, 2005), (c) the functionality that records and plays back utterances stimulates language learners to produce speech and improve their pronunciation (Demenko, Wagner, \& Cylwik, 2010) and (c) taking photos in real-life contexts can facilitate meaning making of Chinese words (Wong, Chin, Tan \& Liu, 2010).

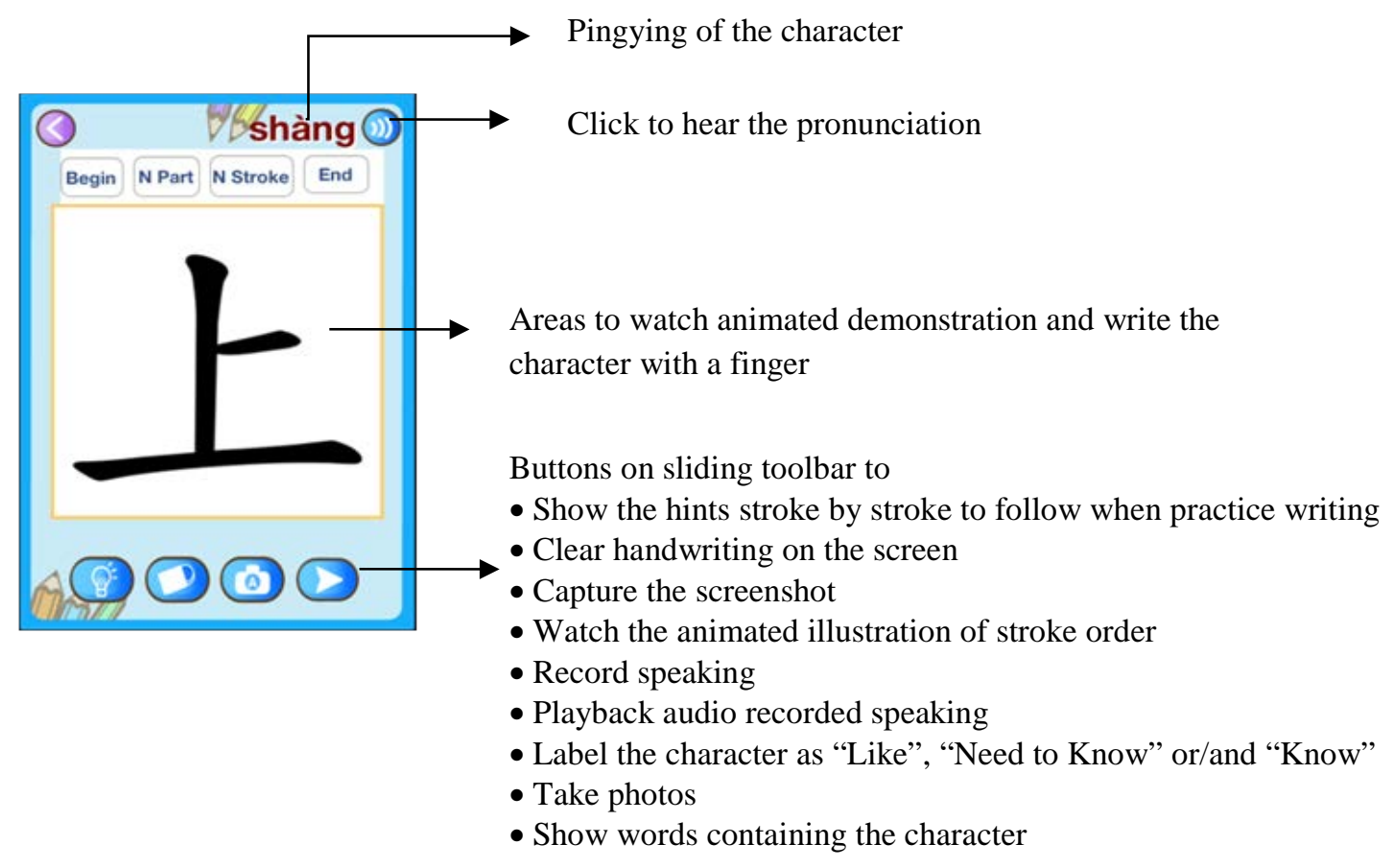

Figure 3. The second screen of Character Library 


\subsubsection{Learning Games Module}

Learning Games was designed as the strategy to intrinsically motivate students to spend more time learning. The function includes two games: and Pinyin Match (Figure 4) and Hearing and Match (Figure 5). To make the games interesting, enjoyable, and challenging, for Prensky's (2013) six elements of fun and engaging digital games were identified and implemented, as illustrated in Table 3.

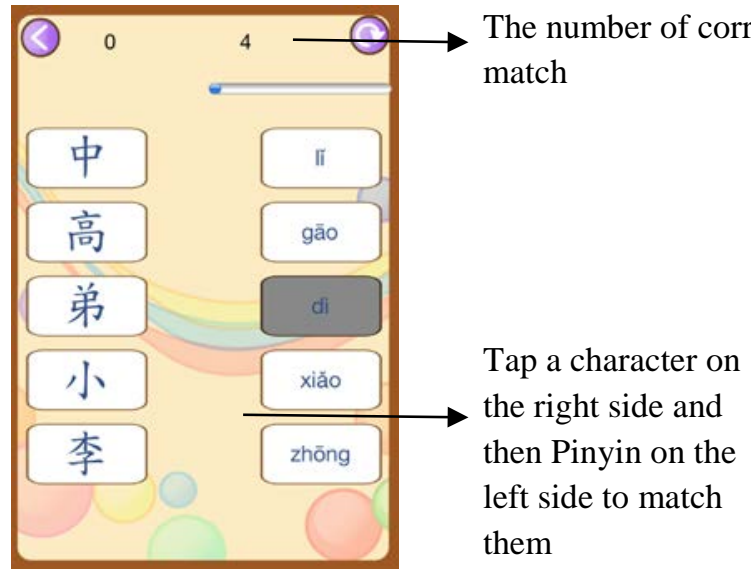

Figure 4. The main screen of Pinyin Match

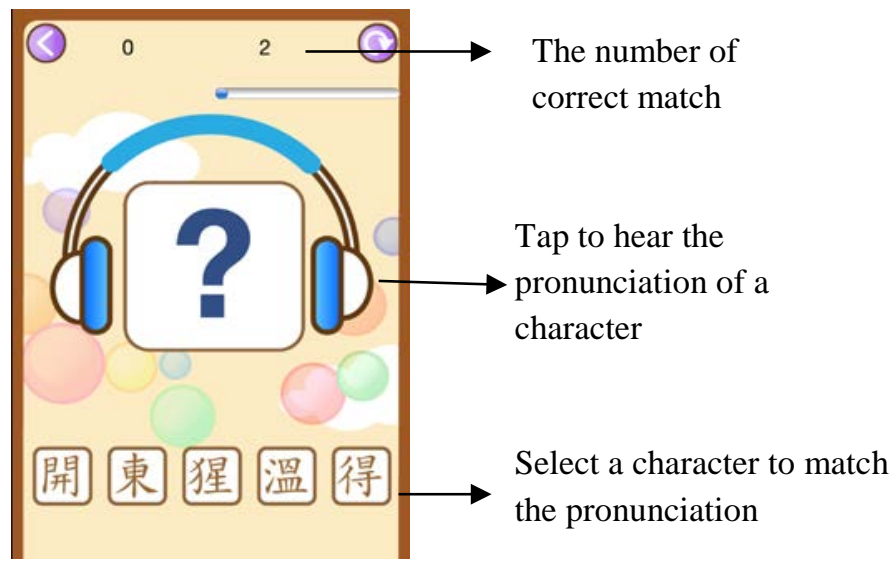

Figure 5. The main screen of Hear and Match

\section{Table 3}

Implementation of elements of fun and engaging digital games

\begin{tabular}{ll}
\hline Elements & Implementation in the App \\
\hline Rules & $\begin{array}{l}\text { Pinyin Match is a game to engage students in associating characters with } \\
\text { correct pinyin. Students should match as many characters as they can with } \\
\text { pinyin during one minute. } \\
\text { Hear and Match is a game to reinforce listening skills. In this game, students } \\
\text { hear the sound and select the related character in one minute }\end{array}$ \\
$\begin{array}{l}\text { Boal and objectives } \\
\text { obtain high scores in the games. }\end{array}$ \\
$\begin{array}{l}\text { Outcome and feedback } \\
\text { Prompt feedback is given to students when they make correct matches in both } \\
\text { games. In Pinyin Match, correctly matched characters and pinyin disappear. In } \\
\text { Hear and Match, the game does not continue until students choose the correct } \\
\text { character. At the end of the games, the systems give scores to players based on } \\
\text { their performances. }\end{array}$ \\
$\begin{array}{l}\text { Students can compete with each other on scores received in the games, or } \\
\text { challenge themselves to surpass their previous records. }\end{array}$ \\
$\begin{array}{l}\text { Conflict, competition, } \\
\text { opposition } \\
\text { Interaction } \\
\text { The representation or } \\
\text { story }\end{array}$ & $\begin{array}{l}\text { Competition on game scores can be carried out in group activities. } \\
\text { exercises. The application represents these two exercises in a game-based } \\
\text { learning approach with children-friendly interface and exciting elements. }\end{array}$ \\
\hline
\end{tabular}




\subsubsection{My Collection Module}

My Collection is a learning portfolio system archiving students' digital artifacts created in the App. The learning portfolio developed during the learning process has been widely used to promote reflection on learning content and process (Bhattacharya, 2001; Knight, Hakel, \& Gromko, 2008). My Collection showcases students' learning artifacts created within the application, as illustrated in Figure 6. It enables students to reflect on their learning process and share their learning achievements with others, which can intrinsically motivate them to learn more. This function enables teachers to assess students' learning performance and progress.

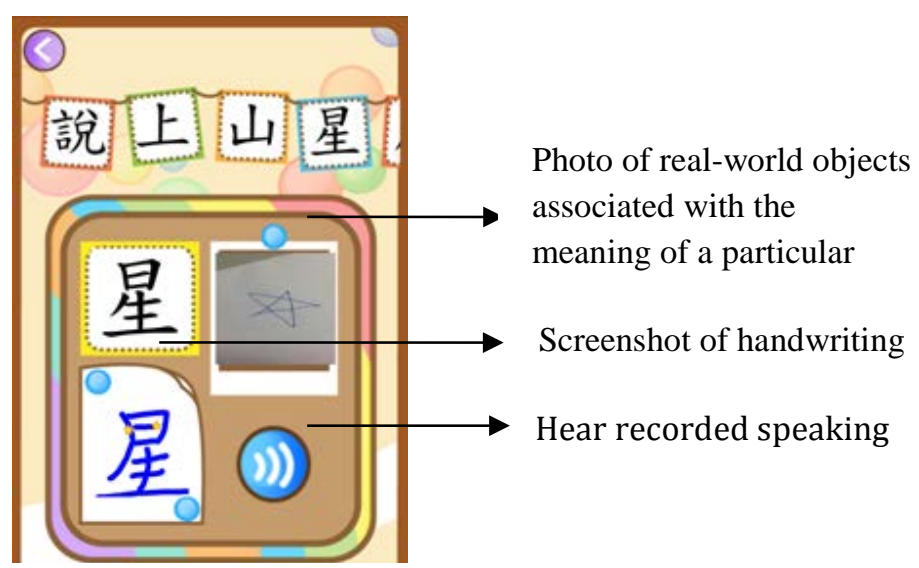

Figure 6. The main screen of My Collection

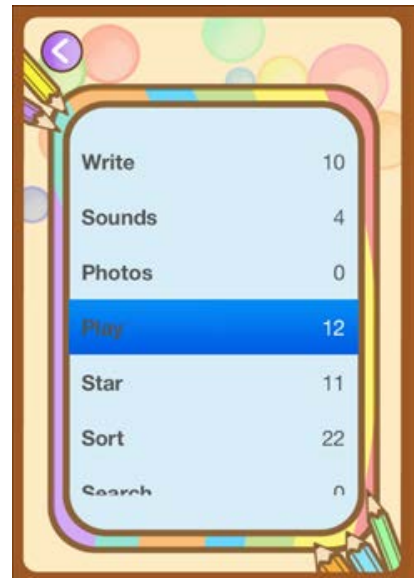

Figure 7. The main screen of My Handbook

\subsubsection{My Handbook Module}

My Handbook is the statistics of students' learning activities within the APP (see Figure 7). It summarizes the information related to different types of learning activities students complete within the application. Using this function, teachers and learners can gain a sense of how many activities have been finished.

\subsection{Interface Design}

The user interface (UI) design of the application by and large followed human interface design principles suggested by Apple's developer website (see http://developer.apple.com). Three main changes were made based on previous version to build friendly user interface for children:

(1) The App adopts a soft, bright, and eye-catching colour theme. Several versions of interface colour theme were shown to students and let them make decision according to their preferences

(2) The layout of the interface is simple in the case that complex UI might confuse children. Take Home Screen as an example. Home Screen was design with few options for navigating to the main functional modules. Students were asked to freely navigate within the prototypes. The instructional designer observed their operations on the App and evaluated the ease of navigating within and between functional modules. Suggestions were then offered to the software engineer for improvement.

(3) Simple gestures—swiping and tapping—were enabled for children to manipulate and navigate within the App . For example, students swipe the sliding toolbar at the bottom of the second screen of Character Library to tap a button (see Figure 2.).

\section{Evaluation of the App}

The App was evaluated by teachers and students in real learning environments. The purposes of the evaluation were to assess the ability of the App to (a) satisfy teachers' pedagogical needs, (b) assist students in learning Chinese characters, and (c) arouse and sustain students' learning interests. After four participating teachers experimented the App for two months, the instructional designer observed twelve lessons taught in order to understand how the teachers integrated the 
App into classroom teaching, and how learners used App in their learning activities. The data from the classroom observations reveals that the App had been mainly used in four different ways:

(1) The App was used in combination with workbooks as a tool for demonstration, practice, and reference. For example, students used the application to watch demonstrations and practice writing in correct stroke order first (see Figure 8A). They then used the workbook to practice handwriting with pencils while writing down a sentence constructed with the character. They referred to the Character Library when encountering unknown characters.

(2) The App was used to independently practice writing and speaking. Students in groups received a sheet listing the characters they needed to review and practice (see Figure 8B). They took the screenshot of their writing and recorded their speaking of a sentence constructed with the character. In most cases, students played back their recorded speaking immediately. They learned independently under the supervision of a teaching assistant. The teaching assistant assessed students' learning performance by checking their learning artifacts saved in $M y$ Collection in the App.

(3) The App was used to support game-based group learning for reinforcing pinyin pronunciation and listening skills. In addition to playing the games individually, students were grouped to play Pinyin Match and Hear and Match under the supervision of a teaching assistant (see Figure 8C). They showed their scores and competed with one another. Students looked excited due to this competitive game-based engagement.

(4) The App was used to facilitate characters' meaning making by taking photos of real-world objects. For example, in a class, students initially drew pictures that related to the meaning of the characters on a white paper, and then took photos of their drawings to store it in the App (see Figure 8D). In another example, students took their iPod Touches home and captured photos of the real-world objects that associate them with characters they were learning

The data from the observations shows that almost all students could fluently operate the App to in learning activities. Students were engaged and responsive. The analysis of 17 students' learning artifacts supports the findings of the observation, including 259 screenshots of handwriting, 357 audio files, and 41 photos stored in the iPod Touches. The results indicated that with the assistance of the App, almost all students were capable of writing as well as pronouncing characters correctly; nearly two thirds of photos taken by the students are related to the meanings of characters.

The teachers reported there were observable improvements in aspects of language learning, and students' interests and engagement in writing characters, especially for those with low levels of Chinese language ability. According to the interview data, the App was capable of satisfying their pedagogical requirements for differentiated instruction by enriching group activities, accommodating a variety of learning abilities, and encouraging students to input and output of language. All of the teachers felt that the App saved time previously spent on repeated demonstration; more importantly, it greatly engaged students by increasing their learning interests and confidence. It removed the barrier of limited vocabulary of primary school students and allowed them to be more creative in sentence construction through speaking it out rather than writing. The scaffolding offered by the App was considered particularly helpful for students with lower 
levels of Chinese language ability to master the correct procedure of writing a character. They further suggested that it was important that the App had a built-in capability that could adapt to and challenge various levels of Chinese language abilities. Another suggested feature was a function of recording writing process of characters for assessment of stroke order execution, because this could hardly be achieved without the help of technology. Inspired by the affordances of the App, the teachers were challenged to explore the new instructional methods and willing to keep trying it.

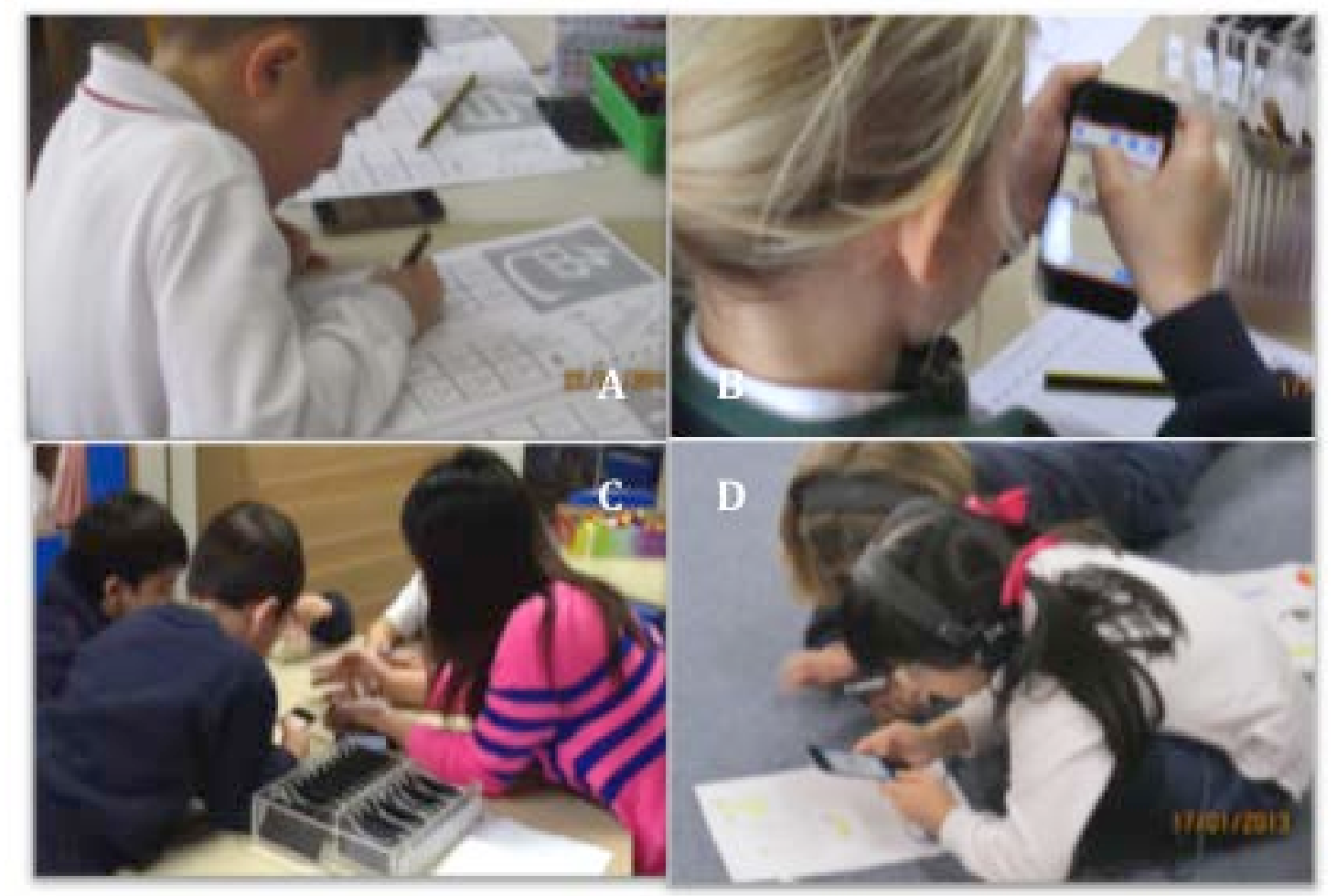

Figure 8. Four ways of using the App in the classroom

The results of students' interviews were generally consistent with that of teachers' interviews. A list of simple questions was posed to the same 17 students who participated in tell-and-show previously regarding their attitudes toward the usefulness of the application for Chinese learning. Some questions were: Do you like the app? Why or why not? Does the application help you to learn to read, write, and speak Chinese? How do you know this? Fifteen of the 17 students stated that they enjoyed learning with the application because it made writing Chinese characters more fun than with pencil and paper. The majority (13 out of 17) felt that their writing, reading, and speaking were improved with the help of the App. They felt a sense of achievement when they reviewed what they had achieved through My Collection. Two students also mentioned that they were fond of sharing their writing and photos stored within the App with their parents and other students. To facilitate sharing, a social networking feature that empowers students to post and share their own learning artifacts should be welcomed. Nevertheless, four students felt neutral as they had mastered characters prior to using the application. All students indicated that they would like to continue using the App in Primary Year 2.

In conclusion, the data from this particular context indicates that the built-in affordances of this App can support teaching and learning of Chinese characters in terms of writing, speaking, listening and meaning making. Primary school students could smoothly operate the App, and most enjoyed learning with it. The design of the App is effective for Chinese character learning in this particular context.

\section{Discussion and Recommendations}

\subsection{Use of the App to Support Chinese Language Learning}


The App in this project was designed to support learning of Chinese characters via iPod touch technology in the context of a bilingual primary school The App consists of four main functional modules, providing functionality for studying and practicing writing, listening, and speaking a fundamental set of Chinese characters. Drawing upon findings of previous research and perspective of educational professionals, the design took into account many elements that promote the effectiveness of Chinese character teaching and learning. The results of the evaluation suggest that the functionality of the App is useful for engaging primary school students in learning Chinese characters in an effective and enjoyable manner; it can be used to implement self-directed individual learning, game-based learning, and group learning. For teachers, this App can help them decrease workload, implement differentiated instruction, and increase students' learning interests as well as confidence. The affordances of the App challenges traditional mindset of teachers and drive them to transform teaching practices.

The advantages of this App over the computer-based multimedia courseware are obvious. The technical features of contemporary mobile technologies — in this project, the iPod Touch—enable students to effortlessly input and output information in a variety of formats to learn language. Students are not confined by fixed devices and can use a variety of tools supported by mobile technology (e.g., camera features). The mobility of the iPod Touch enables children to learn while walking around in the classroom, on their way home, or any other places whenever they feel like learning. However, computer-based multimedia courseware requires certain levels of technical competency to successfully accomplish learning tasks, such as typing with keyboards and handling the mouse, which is challenging for lower-grade students (Wong, Chai, \& Gao, 2011). Writing with fingers on tangible user interface of the mobile devices is more intuitive, fun and close to handwriting experience. There is evidence that interaction with tangible user interface may reduce cognitive load (Kim \& Maher, 2008). Compared to other related mobile applications, this App was particularly designed for primary school students and involved practicing Chinese language teachers in all critical stages of the application development.

Drawing upon experiences derived from the project, recommendations are made for teachers to facilitate Chinese learning with this and other similar Apps:

- A combination of mobile technology and workbook could take advantage of two media. Writing on workbook is the only way to exercise character presentation which is an essential part of Chinese culture and also prevents students from being over dependent on technology. On the other hand, use of the App creates a multimedia language environment to enable multiple forms of input and output of language.

- The App can serve as a tool to facilitate independent learning, game-based learning, and group learning.

- The App can be used to capture students’ learning process for formative assessment.

- $\quad$ The App can be used to cater for various learning needs and abilities of students.

- The App-based learning environment is more suitable for children as mobile technology is relatively easy to manipulate compared with computers.

- Teacher can consider use of mobile technology to raise learning interests and create a sense of learning ownership.

\subsection{Design of Apps for Chinese Language Learning}

Table 4 summarizes a list of features that are proven to be effective in supporting Chinese language learning in this project, and these that can be further developed in the future. It is hoped that information in this table could be useful to inform design decisions of Apps related to Chinese language learning in the future.

Table 4

A list of features supported by evidences to be useful for Chinese language learning

\begin{tabular}{llll}
\hline Features of the App & $\begin{array}{l}\text { Evidences supporting the usefulness of } \\
\text { feature design }\end{array}$ & $\begin{array}{l}\text { Features } \\
\text { development }\end{array}$ & for further
\end{tabular}


- Recording speaking and playing it back

- Capturing screenshot of written characters

- Taking photos associated with the meaning of character

- Supporting game-based exercises

- Archiving and organizing learning artifacts in a portfolio

- Demonstrating the process of constructing a character through animations

- Supporting direct writing on tangible interface

- Providing animated hints of correct stroke sequence while writing

- Offering instant feedback when students make errors in writing
- Students were engaged with exercises delivered in a game manner.

- Teachers were enabled to check students' learning progress

- Student learning interests were enhanced

- Students could correctly associate the meaning of characters with real-world objects

- Students could accomplish independent learning with the App

- Students felt a sense of achievement while reviewing their own learning products stored in the App

- Students were enabled to share their learning products with parents and peers

- Students with limited vocabulary were enabled to record constructed sentences rather than being stuck with unknown characters

\section{Conclusion}

This paper describes how a Chinese language learning App was developed for and used in the context of a bilingual primary school. This project demonstrates the great potentials of mobile technology as a learning tool for Chinese language education. The capabilities of mobile technology can be utilized to design Apps that engage learners to learn and practice listening, writing, and speaking independently. This paper should be useful for both Chinese language teachers and software designers. For teachers, recommendations are made in terms of how this App and other similar ones can be useful for supporting Chinese language learning. This App is an effort incorporating perspectives from an instructional designer, a Chinese language expert, and four practicing teachers. Therefore, for software designers, this paper can serve as reference for designing Chinese language learning App in the future.

Acknowledgement: This collaborative project was supported by a grant from Hong Kong Chinese international School and The University of Hong Kong. Special thanks to teachers form the schools who assisted in the project. 


\section{References}

Abras, C., Maloney-Krichmar, D., \& Preece, J. (2004). User-centered design.Bainbridge, W. Encyclopedia of HumanComputer Interaction. Thousand Oaks: Sage Publications, 37(4), 445-56.

Bhattacharya, M. (2001). 'Electronic Portfolios, Student Reflective Practices, and the Evaluation of Effective Learning'. Australian Association for Research in Education-2001 conference proceedings. Fremantle, Australia.

Churchill, D. (2008). Learning objects for educational applications via PDA technology. Journal of Interactive Learning Research, 19(1), 5-20.

Churchill, D., Fox, R. M. K., \& King, M. (2012). Study of affordances of iPads and teacher's private. Technology, 2(3), 251254.

Demenko, G., Wagner, A., \& Cylwik, N. (2010). The Use of Speech Technology in Foreign Language Pronunciation Training. Archives of Acoustics, 35(3), 309-329.

Estellés, E., González, F., \& del Moral, E. (2010). Social Bookmarking Tools as Facilitators of Learning and Research Collaborative Processes: The Diigo Case. Interdisciplinary Journal of E-Learning \& Learning Objects, 6.

Giovanni (1994). Order of strokes writing as a cue for retrieval in reading Chinese characters. European Journal of Cognitive Psychology,6(4), 337-355.

Kim, M. J., \& Maher, M. L. (2008). The impact of tangible user interfaces on spatial cognition during collaborative design. Design Studies, 29(3), 222-253.

Knight, W. E., Hakel, M. D., \& Gromko, M. (2008). The Relationship Between Electronic Portfolio Participation and Student Success. Professional File Number 107, Spring 2008. Association for Institutional Research.

Kukulska-Hulme, A., \& Traxler, J. (Eds.). (2007). Mobile learning: A handbook for educators and trainers. Routledge.

Prensky, M. (2003). Digital game-based learning. Computers in Entertainment (CIE), 1(1), 21-21.

Shen, H. H. (2004). Level of cognitive processing: Effects on character learning among non-native learners of Chinese as a foreign language.Language and Education, 18(2), 167-182.

So, Dominica, \& Siegel, LindaS. (1997). Learning to read Chinese: Semantic, syntactic, phonological and working memory skills in normally achieving and poor Chinese readers. Reading and Writing, 9(1), 1-21. doi: 10.1023/A:1007963513853

Tan, Li Hai, Spinks, John A., Eden, Guinevere F., Perfetti, Charles A., \& Siok, Wai Ting. (2005). Reading depends on writing, in Chinese. Proceedings of the National Academy of Sciences of the United States of America, 102(24), 87818785. doi: 10.1073/pnas.0503523102

Wang, L. (2005). The impact of multimedia on Chinese learners' recognition of characters: A quantitative and qualitative study.

Wang, J., \& Leland, C. H. (2011). Beginning students' perceptions of effective activities for Chinese character recognition. Reading in a Foreign Language, 23(2).

Wong, L. H., Chai, C. S., \& Gao, P. (2011). The Chinese Input Challenges for Chinese as Second Language Learners in Computer-Mediated Writing: An Exploratory Study. Turkish Online Journal of Educational Technology, 10(3).

Wong, L.-H., Chin, C.-K., Tan, C.-L., \& Liu, M. (2010). Students' Personal and Social Meaning Making in a Chinese Idiom Mobile Learning Environment. Educational Technology \& Society, 13 (4), 15-26. 